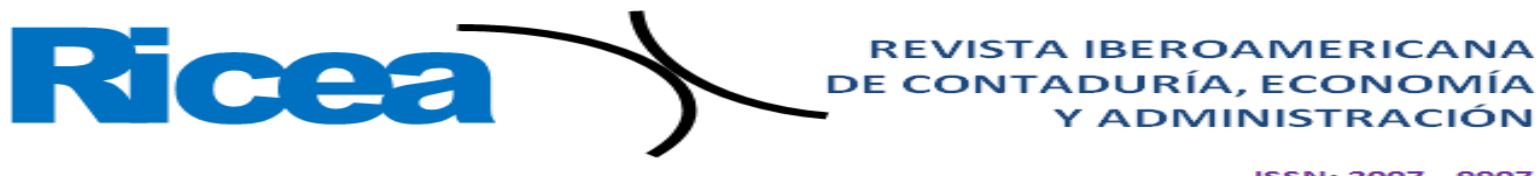

https://doi.org/10.23913/ricea.v9i18.152

Artículos Científicos

\title{
La expansión urbana dispersa y su relación con las dinámicas inmobiliarias en Tlajomulco de Zúñiga, Jalisco
}

The Dispersed Urban Expansion and Its Relationship with Real Estate
Dynamics in Tlajomulco de Zúñiga, Jalisco

Expansão urbana dispersa e sua relação com a dinâmica imobiliária em Tlajomulco de Zúñiga, Jalisco

Héctor Hernández García

Universidad de Guadalajara, México hhgdoc2017@gmail.com https://orcid.org/0000-0001-5888-5970

Myriam Guadalupe Colmenares López

Universidad de Guadalajara, México myriam.colmenares@academicos.udg.com https://orcid.org/0000-0002-4124-5595

\section{Resumen}

La presente investigación tiene como finalidad exponer un análisis exploratorio sobre la relación entre la expansión urbana dispersa iniciada en 1990 y consolidada en el año 2015 en el municipio metropolitano y periférico de Tlajomulco de Zúñiga, Jalisco, y las acciones de los desarrolladores inmobiliarios, en específico la construcción de conjuntos residenciales que reestructuraron socioespacialmente el municipio. La estrategia metodológica comprende la realización de tres fases de análisis, donde se utilizan métodos y técnicas tanto cuantitativas (estadísticas y cartográficas) como cualitativas (entrevistas). Los fraccionamientos asentados en la porción sureste del municipio de Tlajomulco de Zúñiga fueron impulsados por los actores inmobiliarios con la intención de aprovechar el precio del suelo; al final, sin embargo,

\section{(c) 9}




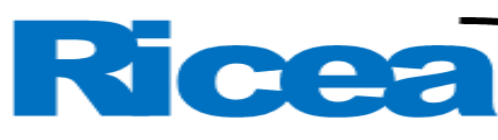

REVISTA IBEROAMERICANA DE CONTADURÍA, ECONOMÍA Y ADMINISTRACIÓN

ISSN $=2007-9907$

generaron espacios alejados en tiempo y distancia de los centros administrativos y de servicios. Además, configuraron formas irregulares de fraccionamientos con trazos urbanos internos largos que exacerban el círculo virtuoso de desvalorización del suelo y la vivienda, lo que ha generado dificultad para dotar de servicios de transporte y agua y provocado esquemas de segregación y exclusión social.

Palabras clave: dispersión urbana, Tlajomulco de Zúñiga, valor de la vivienda.

\section{Abstract}

The purpose of this research is to present an exploratory analysis on the relationship between the dispersed urban expansion started in 1990 and consolidated in 2015 in the metropolitan and peripheral municipality of Tlajomulco de Zúñiga, Jalisco, and the actions of real estate developers, specifically the construction of residential complexes that restructured the municipality socio-spatially. The methodological strategy includes the performance of three phases of analysis, where both quantitative (statistical and cartographic) and qualitative (interviews) methods and techniques are used. The subdivisions settled in the southeastern portion of Tlajomulco de Zúñiga were promoted by real estate actors with the intention of taking advantage of the land price; in the end, however, they generated spaces that were far away in time and distance from administrative and service centers. In addition, they configured irregular forms of subdivisions with long internal urban lines that exacerbate the virtuous circle of devaluation of land and housing, which has made it difficult to provide transport and water services and caused patterns of segregation and social exclusion.

Keywords: urban dispersion, Tlajomulco de Zúñiga, housing value. 


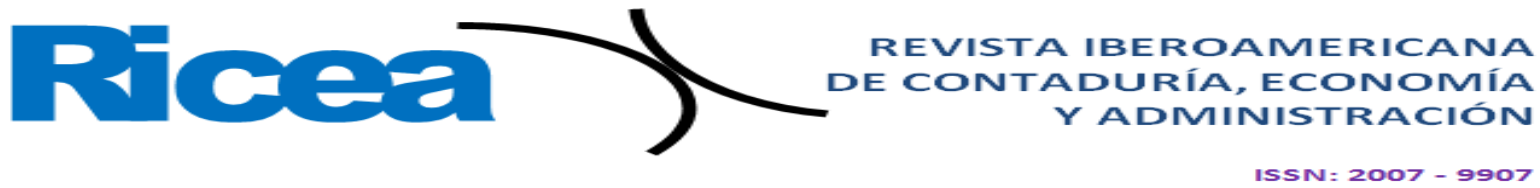

\section{Resumo}

O objetivo desta pesquisa é apresentar uma análise exploratória sobre a relação entre a expansão urbana dispersa iniciada em 1990 e consolidada em 2015 no município metropolitano e periférico de Tlajomulco de Zúñiga, Jalisco, e as ações das incorporadoras imobiliárias, especificamente a construção de conjuntos residenciais que reestruturaram o município socioespacialmente. A estratégia metodológica inclui a realização de três fases de análise, onde são utilizados métodos e técnicas quantitativas (estatísticas e cartográficas) e qualitativas (entrevistas). Os loteamentos implantados na parte sudeste do município de Tlajomulco de Zúñiga foram promovidos por agentes imobiliários com o intuito de aproveitar o preço do terreno; No final, porém, geraram espaços distantes no tempo e distantes dos centros administrativos e de serviços. Além disso, configuraram formas irregulares de loteamentos com longas linhas urbanas internas que exacerbam o círculo virtuoso de desvalorização do solo e da habitação, que dificultou a prestação de serviços de transporte e água e gerou padrões de segregação e exclusão social.

Palavras-chave: dispersão urbana, Tlajomulco de Zúñiga, valor habitacional.

Fecha Recepción: Febrero 2020 Fecha Aceptación: Julio 2020

\section{Introducción}

En las periferias de las ciudades de América Latina se han emprendido procesos de expansión dispersa de asentamientos humanos en donde predominan habitantes de bajos ingresos y en donde las dinámicas económicas del mercado de suelo y vivienda se convierten en fundamento y promotor de la transformación urbana de las ciudades contemporáneas (Alegría y González, 2016; Colmenares, 2015; Fitch, 2016; Monkkonen y Comandon, 2016). Al respecto, algunos estudios en México han realizado comparativas entre ciudades o áreas metropolitanas sobre la dispersión urbana ${ }^{1}$ que presentan (Secretaría de Desarrollo Social [Sedesol], 2011).

\footnotetext{
${ }^{1}$ En los estudios de análisis comparativos de dispersión urbana entre ciudades se identifica al área metropolitana de Guadalajara con mayor crecimiento de su superficie respecto a su población (en superficie creció 3.82 veces y en población 1.98 veces). El municipio de Tlajomulco de Zúñiga forma parte relevante de su expansión física, sobre todo en el periodo 2000-2010 (Instituto Nacional de Estadística y Geografía [Inegi], 1990, 2000, 2010).
} 


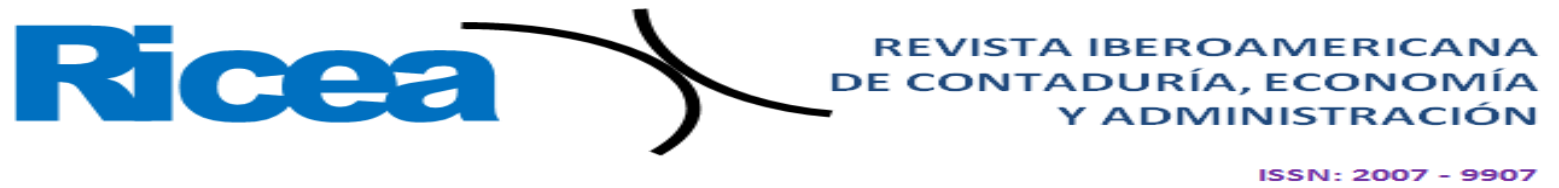

En la mayoría de los estudios, el actor inmobiliario define cómo y dónde construir en el suelo urbano, bajo las normas institucionales que correspondan, y lo hace a partir de las proyecciones de rentabilidad sobre el tipo de demanda final que esperan suscitar con sus desarrollos inmobiliarios según el principio del "mejor y mayor uso"2 (Colmenares, 2015; Eckert, 1990; Erba, 2013; Smolka, 1981;). Además de las predicciones sobre la disposición de pago de los consumidores finales, que no son sencillas, se debe tomar en cuenta el tiempo de producción de los bienes inmobiliarios, capacidad de pago de los demandantes finales, los niveles y la distribución del ingreso, la inflación y la política crediticia.

Por ello, resulta de gran interés exponer la relación entre la expansión urbana dispersa y las acciones de los desarrolladores inmobiliarios, la construcción de conjuntos residenciales, que reestructuraron socioespacialmente el municipio de Tlajomulco de Zúñiga (Jalisco) en los últimos 15 años. Sobre todo por la concentración de población de bajos ingresos que se encuentra alejada del centro económico, lo cual refuerza la existencia de problemas sociales, especialmente para los asentamientos sociales con carencias de accesibilidad, servicios y equipamientos urbanos de calidad, así como la desintegración social vinculada a las desventajas que conlleva el aislamiento físico (Bazant, 2009; Colmenares, 2015; Monkkonen y Comandon, 2016; Sabatini y Sierralta, 2006).

\section{La dispersión urbana}

El concepto de dispersión urbana fue utilizado por primera vez en el primer párrafo de un artículo escrito por el sociólogo William Whyte en la revista Fortune, en 1958. Entre los primeros estudios sobre la dispersión del territorio están los escritos en "Estados Unidos, por el crecimiento anárquico e ilimitado de las áreas periurbanas generado después de la Segunda Guerra Mundial; para los países de Europa, el fenómeno se presenta a partir de los años 60 del siglo XX” (Giampino, 2010, p. 30, citado en González, 2015, p. 40).

En un estudio reciente sobre dispersión urbana asociada a los costos en la administración pública se mencionan diversas dimensiones en la búsqueda de medición de la dispersión urbana (Gielen, 2016). Como sea que fuere, la mayoría de los autores y estudios

\footnotetext{
${ }^{2}$ El principio de "mejor y mayor uso" es aquel que, siendo físicamente posible, legalmente permitido y económicamente viable, resulta en el mayor valor del bien que se está valuando. Este principio se toma en cuenta para representar estados financieros; implica un análisis de las condiciones intrínsecas del bien, las normas legales que lo afectan y los cambios económicos que impacten en dicho bien para estimar su valor (Colmenares, 2015; Eckert, 1990; Erba, 2013; Smolka, 1981).
} 
analizados coinciden en que las variables de densidad, centralidad, continuidad o fragmentación son referentes en su definición como se muestra en la tabla 1.

Tabla 1. Principales dimensiones en la medición de la dispersión urbana

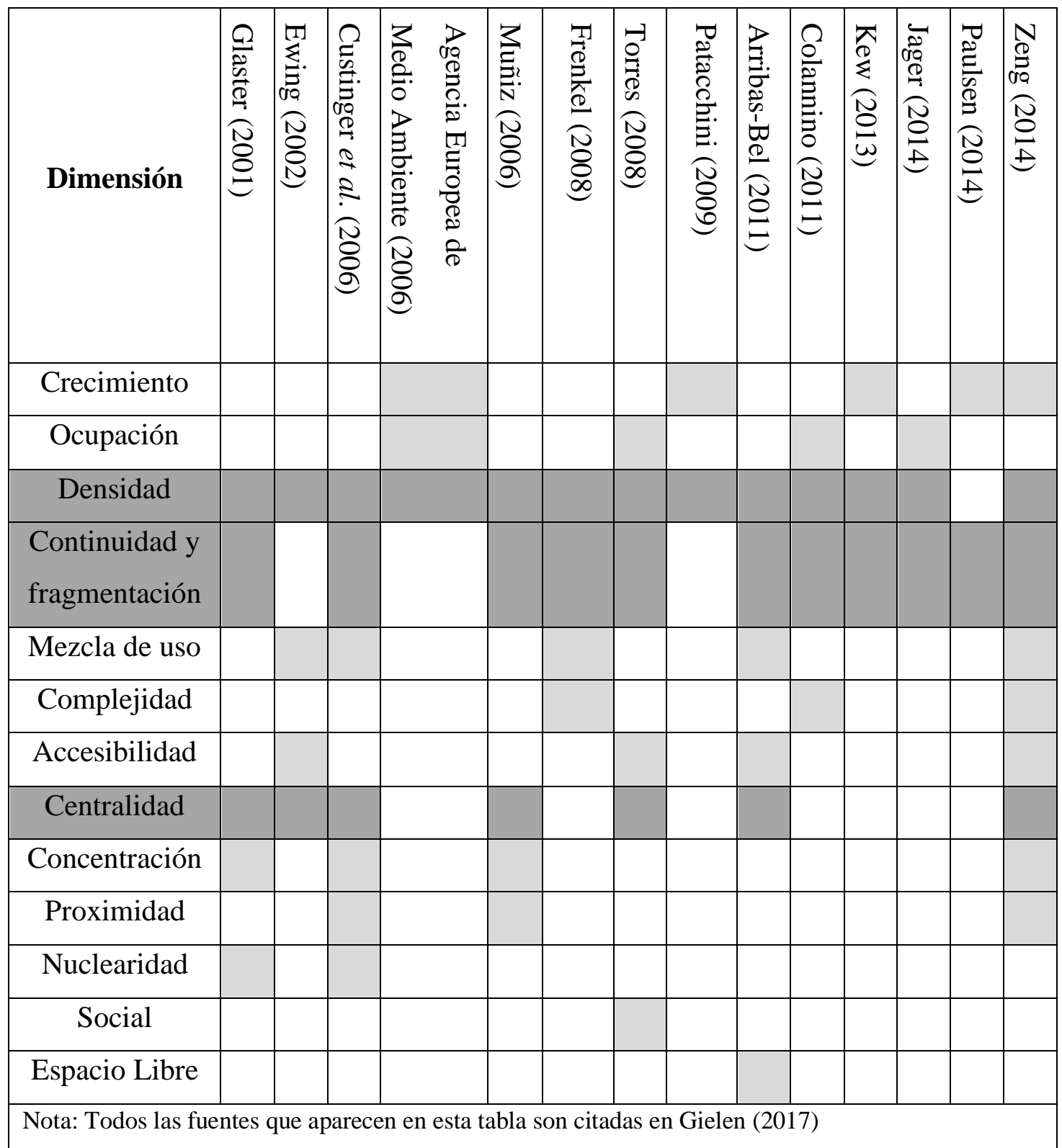

Fuente: Elaboración propia con base en Gielen (2017)

En Europa se le ha dado un importante peso económico al concepto de dispersión urbana. La Agencia Europea de Medio Ambiente [AEMA] (2006), dentro de su informe titulado Urban sprawl in Europe. The ignored challenge [EEA] (2006), define a la dispersión urbana, en el contexto de la expansión urbana, de la siguiente manera: 


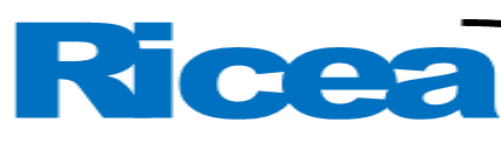

REVISTA IBEROAMERICANA DE CONTADURÍA, ECONOMÍA Y ADMINISTRACIÓN

ISSN $=2007-9907$

El patrón físico de la expansión de baja densidad de grandes áreas urbanas, en condiciones de mercado, principalmente en las zonas agrícolas circundantes. La dispersión es la ventaja principal del crecimiento urbano e implica poco control de la planificación de la subdivisión de la tierra. El desarrollo es desigual, disperso y encadenado, con una tendencia a la discontinuidad. Salta-ranas sobre áreas, dejando enclaves agrícolas. Las ciudades extensas son opuestas a las ciudades compactas, llenas de espacios vacíos que indican las ineficiencias en el desarrollo y destacan las consecuencias del crecimiento no controlado (p. 6).

En el presente trabajo se retomaron dos dimensiones de la dispersión utilizadas por la mayoría de autores que han abordado la temática, a saber: la continuidad y la centralidad. Aunado a ello, se integró la variable de complejidad del plano urbano, dada las características irregulares de los fraccionamientos elegidos para el estudio.

\section{La expansión urbana de Tlajomulco de Zúñiga}

El ritmo de crecimiento del municipio ha estado por encima del ritmo de crecimiento del estado de Jalisco o del Área Metropolitana de Guadalajara (AMG), con tasas que oscilan entre $5.69 \%$ (de 1990 a 2000) y $12.92 \%$ (en el periodo 2000-2010) (Inegi, 1990, 2000, 2010). Mientras que a nivel metropolitano y estatal oscilan entre $1.31 \%$ y $2.12 \%$, respectivamente.

En el año de 1990, la cabecera municipal era la única localidad que superaba los 10000 habitantes al tener 11567 (16 \% de la población municipal). Para el año 2000, aparecen otras localidades con igual o mayor tamaño (Inegi, 1990 y 2000). En el año 2015, el municipio de Tlajomulco de Zúñiga contaba con una población de 549442 personas (Inegi, 2015), lo que correspondía a $11.2 \%$ de los habitantes del total del AMG. 


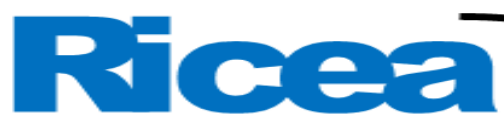

REVISTA IBEROAMERICANA DE CONTADURIAA, ECONOMÍA

Tabla 2. Evolución del crecimiento de localidades por su tamaño poblacional en el municipio de Tlajomulco de Zúñiga, Jalisco (1990-2010)

\begin{tabular}{|c|r|r|r|r|r|r|}
\hline \multirow{2}{*}{$\begin{array}{c}\text { Tamaño de } \\
\text { Localidad }\end{array}$} & \multicolumn{2}{|c|}{$\mathbf{1 9 9 0}$} & \multicolumn{2}{|c|}{$\mathbf{2 0 0 0}$} & \multicolumn{2}{|c|}{$\mathbf{2 0 1 0}$} \\
\cline { 2 - 7 } & Localidades & Habitantes & Localidades & Habitantes & Localidades & Habitantes \\
\hline 1-99 hab. & 166 & 1661 & 203 & 3362 & 221 & 8651 \\
\hline 100-999 hab. & 16 & 7949 & 8 & 2624 & 8 & 5201 \\
\hline 1000-1999 hab. & 7 & 9672 & 11 & 16820 & 16 & 28732 \\
\hline 2000-4499 hab. & 4 & 13806 & 7 & 22827 & 7 & 24721 \\
\hline 5000-9999 hab. & 3 & 23773 & 3 & 18851 & 9 & 66780 \\
\hline 10 000-14 999 hab. & $\mathbf{1}$ & 11567 & $\mathbf{3}$ & 42958 & $\mathbf{5}$ & 60492 \\
\hline 15 000-19 999 hab. & & & $\mathbf{1}$ & 16177 & $\mathbf{5}$ & 135114 \\
\hline 20 000-99 999 hab. & & & & & $\mathbf{1}$ & 86935 \\
\hline Totales & $\mathbf{1 9 7}$ & $\mathbf{6 8 ~ 4 2 8}$ & $\mathbf{2 3 6}$ & $\mathbf{1 2 3 ~ 6 1 9}$ & $\mathbf{2 7 2}$ & $\mathbf{4 1 6 ~ 6 2 6}$ \\
\hline
\end{tabular}

Fuente: Elaboración propia con base en Inegi (1990, 2000, 2010)

En la tabla 2 se muestra que en el año de 1990 el municipio contaba con solo 15 localidades con una población mayor a 1000 habitantes. Para el año 2000, sin embargo, ya contaba con 25 localidades que alcanzaban o superaban esta cifra, y finalmente para el año 2010 hay un incremento de 43 localidades con más de 1000 habitantes. Varias de ellas se asentaron de forma dispersa y fragmentada: un gran reto si se quiere construir un proyecto integral de infraestructura orientado a generar cohesión social en el municipio.

Para el año 2010, se cuenta con 11 localidades con más de 10000 habitantes, donde la suma de su población representa $67.81 \%$ del municipio. Cabe señalar que, en este periodo, las localidades de Hacienda Santa Fe y San Agustín rebasaron la cantidad de población de la cabecera municipal, como se puede observar en la tabla 3. 


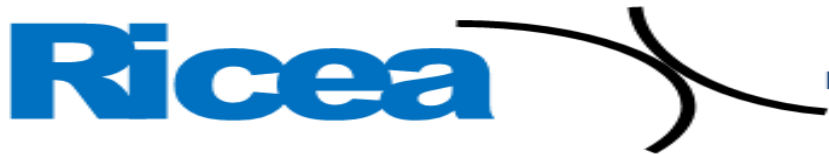

REVISTA IBEROAMERICANA DE CONTADURIAA, ECONOMIA

Tabla 3. Evolución del crecimiento de localidades mayores a 10,000 habitantes en el municipio de Tlajomulco de Zúñiga, Jalisco (1990- 2010)

\begin{tabular}{|c|c|c|c|c|c|c|}
\hline \multirow{2}{*}{$\begin{array}{c}\text { Localidades } \\
\text { mayores a } \\
10000 \\
\text { habitantes }\end{array}$} & \multicolumn{2}{|c|}{1990} & \multicolumn{2}{|c|}{2000} & \multicolumn{2}{|c|}{2010} \\
\hline & Habitantes & $\begin{array}{l}\text { Viviendas } \\
\text { particulares } \\
\text { habitadas }\end{array}$ & Habitantes & $\begin{array}{c}\text { Viviendas } \\
\text { particulares } \\
\text { habitadas }\end{array}$ & Habitantes & $\begin{array}{c}\text { Viviendas } \\
\text { particulares } \\
\text { habitadas }\end{array}$ \\
\hline $\begin{array}{l}\text { Hacienda } \\
\text { Santa Fe }\end{array}$ & & & & & 86935 & 22821 \\
\hline San Agustín & & & 14355 & 3046 & 30424 & 7390 \\
\hline $\begin{array}{l}\text { Tlajomulco } \\
\text { de Zúñiga }\end{array}$ & 11567 & 2115 & 16177 & 3099 & 30273 & 7085 \\
\hline $\begin{array}{c}\text { San } \\
\text { Sebastián el } \\
\text { Grande }\end{array}$ & & & 14695 & 2861 & 28,138 & 6263 \\
\hline $\begin{array}{c}\text { Santa Cruz } \\
\text { del Valle }\end{array}$ & & & 13908 & 2789 & 26866 & 5671 \\
\hline $\begin{array}{c}\text { Lomas del } \\
\text { Sur }\end{array}$ & & & & & 19413 & 5016 \\
\hline $\begin{array}{c}\text { Fraccionami } \\
\text { ento Real del } \\
\text { Valle (El } \\
\text { Paraíso) }\end{array}$ & & & & & 13949 & 3701 \\
\hline $\begin{array}{c}\text { Lomas de } \\
\text { San Agustín }\end{array}$ & & & & & 11836 & 2936 \\
\hline $\begin{array}{c}\text { Fraccionami } \\
\text { ento Villas } \\
\text { de la } \\
\text { Hacienda }\end{array}$ & & & & & 11078 & 2800 \\
\hline La Tijera & & & & & 12425 & 2796 \\
\hline $\begin{array}{c}\text { Santa Cruz } \\
\text { de las Flores }\end{array}$ & & & & & 11204 & 2669 \\
\hline Totales & 11567 & 2115 & 59135 & 11795 & 282541 & 69148 \\
\hline
\end{tabular}

Fuente: Elaboración propia con base Inegi (1990, 2000, 2010)

Las 11 localidades identificadas con una población mayor a los 10000 habitantes tienden a distribuirse en torno a las vialidades principales de López Mateos y 8 de Julio, como se puede observar en la figura 1. 


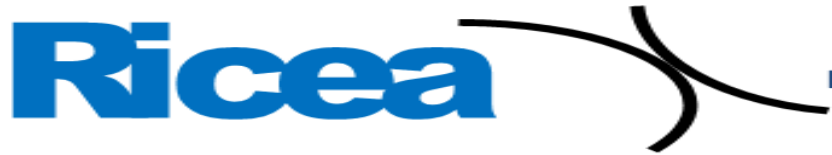

Figura 1. Localidades con más de 10000 habitantes en el municipio de Tlajomulco de Zúñiga, Jalisco, 2010
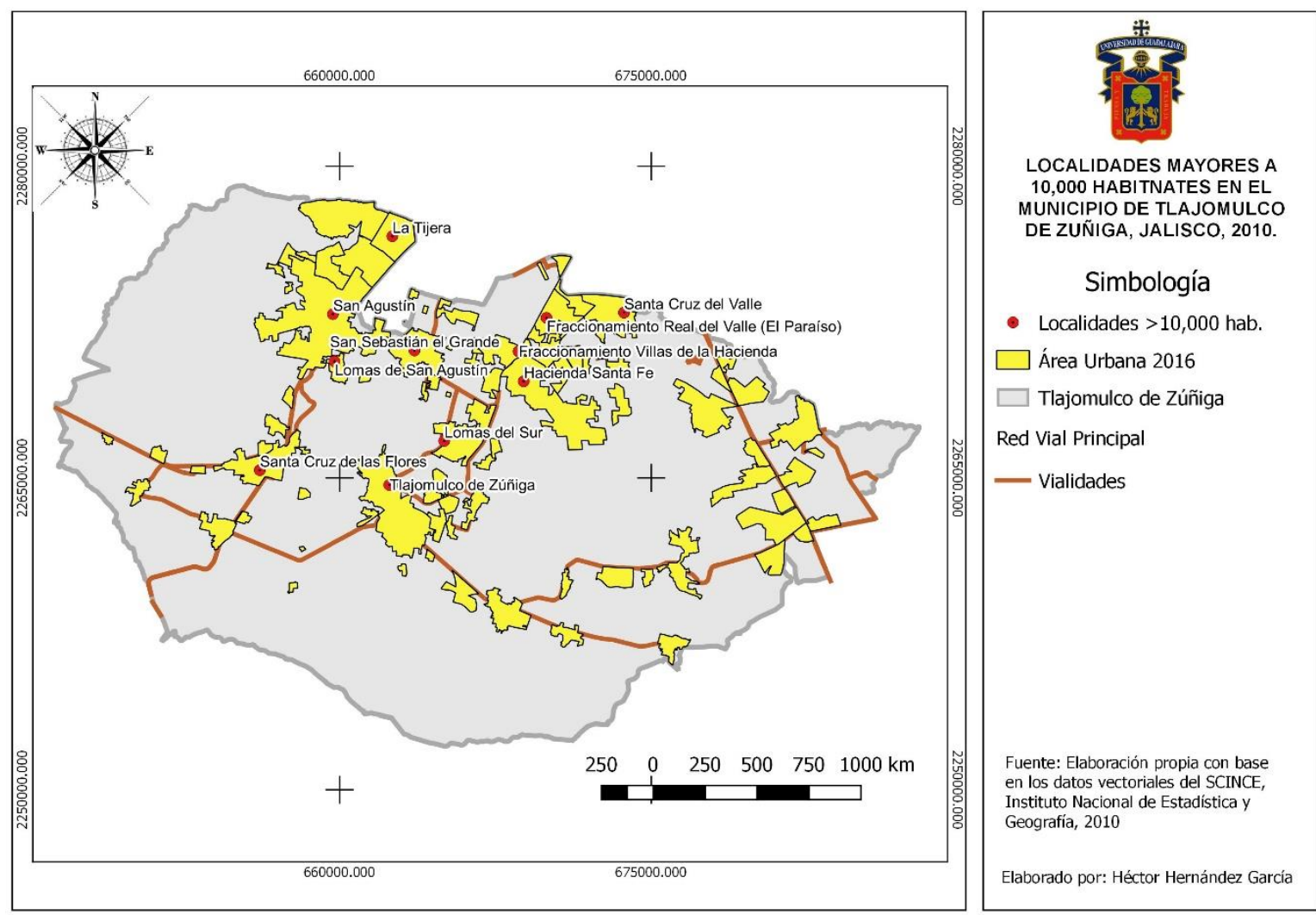

Fuente: Elaboración propia con base en Inegi (2016)

El crecimiento y distribución atomizada de los asentamientos humanos ha traído consigo la conectividad limitada de espacios funcionales, la accesibilidad restringida a distintas áreas dentro del municipio y la escasa integración a la estructura urbana de la ciudad, lo cual refuerza que haya espacios segregados que rayan en la exclusión, sobre todo en la porción sureste del municipio, en los asentamientos que se disponen sobre la carretera a Chapala.

\section{El valor de la vivienda en el mercado inmobiliario}

En México se generó un proceso de expansión urbana y poblacional en la periferia bajo un patrón de baja densidad con usos predominantemente habitacionales. Esto debido al impulso de la vivienda en un escenario de renta de suelo barata en la periferia que, combinado con el nivel de ingresos de los habitantes, provocó un predominante crecimiento de fraccionamientos de vivienda irregular y de tipo popular o económica oficial. 


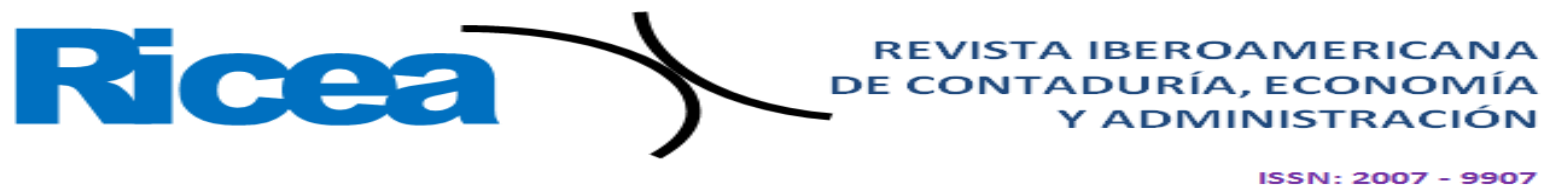

En cuanto al impulso a la vivienda de interés social institucional, el Estado mexicano creó las condiciones que facilitaron el funcionamiento de las empresas privadas por medio del impulso de políticas de financiamiento y adquisición de vivienda; cambios en marcos normativos y la fundación de instituciones que facilitaron la entrada de capital privado y, a su vez, la disminución o el desvanecimiento ${ }^{3}$ del papel regulador del Estado mexicano (Mellado, 2002).

El rol desvanecido del Estado en materia de regulación de la vivienda se acentúa en los años $90,{ }^{4}$ cuando se ponen en marcha instrumentos como el Programa de Fomento y Desregulación de la Vivienda, fundado en octubre de 1992, y se conforman instituciones como la Comisión Nacional de Fomento a la Vivienda (Conafovi), que cambiaría a la actual Comisión Nacional de Vivienda (Conavi), la cual funge como ente coordinador y articulador de las actividades del Gobierno en materia de vivienda. Incluso se le ha asignado promover, respetar, proteger y garantizar el derecho de todos los mexicanos a una vivienda adecuada (Conavi, s. f.).

En este escenario de ventajas económicas para invertir en vivienda, las empresas inmobiliarias integraron proyectos habitacionales completos que iban "desde la adquisición del suelo, su urbanización, la construcción de viviendas, la promoción e incluso, a través de los llamados 'créditos puente', (...) el financiamiento para facilitar su acceso a la población objetivo" (Mellado, 2002 p. 34).

Las acciones de los desarrollos inmobiliarios que influyeron en el proceso de expansión del área urbana se plasmaron en la construcción de grandes conglomerados habitacionales de vivienda social, una vez localizados suelos baratos en las periferias de las ciudades mexicanas (Bazant, 2009; Mellado, 2002). "Estos inmensos conjuntos se caracterizan porque no vienen acompañados de las grandes obras de infraestructura vial y de servicios que se requieren para proyectos de tales dimensiones y las empresas no llevan a cabo estudios de impacto urbano social y ecológico" (Mellado, 2002).

\footnotetext{
${ }^{3}$ El término desvanecer tiene connotaciones económicas y filosóficas profundas y diversificadas que son mencionadas en el libro Todo lo sólido se desvanece en el aire de Marshall Berman y recientemente retomadas por Bauman para desarrollar su concepto de modernidad líquida.

${ }^{4}$ Se constituyeron otras instituciones como la Sociedad Hipotecaria Federal, que impulsó el desarrollo de vivienda. Además, existe el Consejo Nacional de Vivienda (Conavi) que, desde sus inicios y hasta la actualidad, continúa como órgano de consulta del ejecutivo federal e incorpora a los principales actores del sector en la toma de decisiones, pero no solo eso, sino que, de acuerdo con la Ley de Vivienda, tiene como objetivo el proponer medidas para la planeación, formulación, instrumentación, ejecución y seguimiento de la política nacional de vivienda (artículo 28).
}

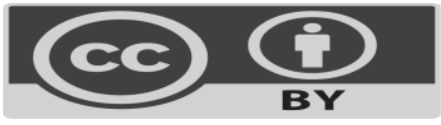




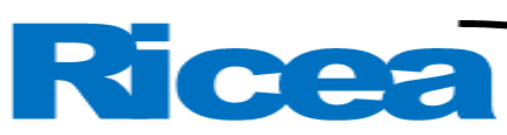

REVISTA IBEROAMERICANA DE CONTADURÍA, ECONOMÍA YADMINISTRACIÓN

Todos estos elementos impulsaron a que las empresas inmobiliarias buscaran suelo barato en un municipio periférico, tal y como Tlajomulco de Zúñiga, donde se volvió determinante para el orden urbano el rol del actor inmobiliario en la gestión de espacios para construcción residencial. De acuerdo con Cruz (2008), entre 2000 y 2006, las intervenciones de los promotores inmobiliarios privados en el municipio de Tlajomulco de Zúñiga fueron las más significativas: representó $89 \%$ de la superficie promovida. Se puede observar claramente que la intervención directa de los organismos públicos de vivienda que se había dado en décadas pasadas, para principios de siglo, cedió su lugar a la promoción privada.

\section{Método}

La estrategia metodológica comprende la realización de tres fases de análisis basadas en la metodología mixta de Arenas (2014, pp. 51-68) que se muestran en la tabla 4. La fase uno corresponde a un breve esbozo del marco conceptual de la dispersión urbana, así como a la descripción y análisis estadístico sociodemográfico y cartográfico del crecimiento demográfico del municipio de Tlajomulco de Zúñiga con respecto a su metrópoli y la entidad.

La fase dos corresponde a la selección de los fraccionamientos tanto desde la perspectiva física, geometrías y distancias, como desde la dimensión social de corte cualitativo por medio del valor de la vivienda y problemáticas de servicios e infraestructura.

En cuanto a los criterios de selección de localidades y fraccionamientos sustentados en el concepto de dispersión urbana se determinaron los siguientes:

1) Centralidad: basado en la teoría de ciudad central o centro de servicios, se entenderá como la distancia lineal al centro principal o nodal de población, servicios, negocios o recreación. En este caso, se aplicará como la distancia lineal del centro de la colonia al centro del AMG o al centro administrativo (cabecera municipal), medida a partir de los centroides.

2) Continuidad: es el grado en que la tierra urbanizable se ha construido sobre las densidades urbanas de una manera ininterrumpida (Harvey y Clark, 1965). Para el estudio se hará la distinción entre el continuo urbano derivado del AMG y las áreas que rompen con la continuidad física de la misma AMG llamadas discontinuas. 
3) Complejidad del plano urbano: se refiere al análisis de los polígonos urbanos que nos permite diferenciar formas compactas como círculos o cuadrados, de manchas lineales o de formas complejas. El indicador más sencillo para caracterizar la forma de un polígono es el radio entre el perímetro y el área de un valor elevado.

4) Valor de la vivienda: valor monetario de la vivienda en el momento de la compra por parte del actual residente del fraccionamiento. Se trata de un indicador asociado a la presencia de dispersión mas no es el único para determinar su formación.

El análisis cualitativo está sustentado en entrevistas semiestructuradas. "La entrevista se puede ubicar conceptualmente como una conversación con un alto grado de intencionalidad planeada, con un objetivo prefijado, sobre el cual se determina el curso de la interacción comunicativa" (Sierra, 1998, p. 297). La entrevista es un proceso de intercambio de información entre una persona y otra(s) a través de preguntas y respuestas que logran una comunicación y la construcción conjunta de significados respecto a un tema (Janesick, 1998, citado en Hernández, Fernández, Baptista, 2010, p. 418).

Se aplicaron seis entrevistas, tres por fraccionamiento seleccionado (fraccionamientos de Arvento y Agaves) correspondiente a las áreas urbanas dispersas de grandes dimensiones.

La selección de los entrevistados fue a través de la técnica bola de nieve, es decir, por medio de las redes sociales naturales, amigos, parientes, contactos personales y conocidos que ayudaron a acceder a los actores objetos de investigación.

Tabla 4. Fases del proceso de análisis y reflexión del estudio

\begin{tabular}{|c|c|c|c|}
\hline Descripción & Fase 1 & Fase 2 & Fase 3 \\
\hline Dimensión & Teórica-conceptual y contexto & $\begin{array}{c}\text { Análisis de casos } \\
\text { concretos }\end{array}$ & Síntesis \\
\hline \multirow{2}{*}{$\begin{array}{c}\text { Tema } \\
\text { desarrollado }\end{array}$} & $\begin{array}{c}\text { Esbozo del concepto de dispersión } \\
\text { urbana }\end{array}$ & Dos casos de análisis & $\begin{array}{c}\text { Reflexión } \\
\text { teórico- } \\
\text { práctica y } \\
\text { discusiones }\end{array}$ \\
\cline { 2 - 4 } & Contexto de expansión física & $\begin{array}{c}\text { Problemáticas } \\
\text { identificadas }\end{array}$ & Conclusión \\
\hline
\end{tabular}

Fuente: Elaboración propia con base en la estrategia del proyecto de investigación Islas Residenciales. Dispersión socio-espacial Residencial en el municipio de Tlajomulco de Zúñiga, Jalisco (1990-2015). 


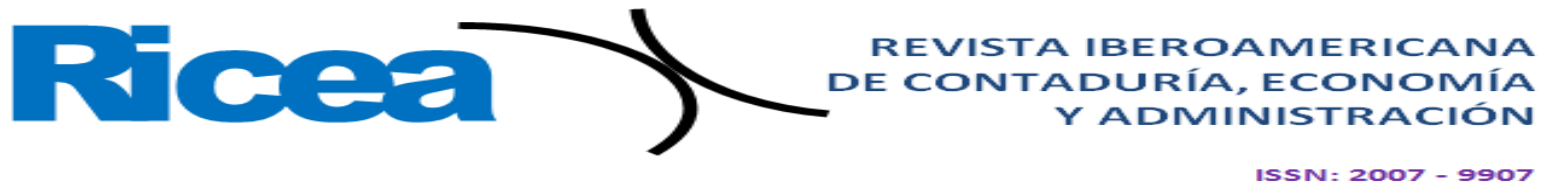

La fase tres se refiere a la reflexión sintética sobre las relaciones identificadas entre tres indicadores de dispersión residencial (Centralidad, discontinuidad y complejidad urbana) con respecto al valor de la vivienda en el momento de venta, así como comportamientos actuales reflejados en la cartografía catastral.

\section{Resultados}

\section{Características de los fraccionamientos}

De las 262 localidades registradas en el año 2010, se determinó analizar a dos que contaran con las tres dimensiones del crecimiento disperso, a saber, de acuerdo con las variables señaladas por Muñiz (2006 y 2013), Zeng (2014) y Gielen (2016), quienes han abordado el tema: 1) grado de centralidad, 2) discontinuidad urbana y 3) complejidad urbana, medida a partir de las formas de los planos urbanos.

Se consideró el valor de la vivienda del periodo cuando estaban desarrollándose los fraccionamientos seleccionados. La herramienta de recolección de datos fue la entrevistasemiestructurada, aplicada a residentes que derivaron de uno a otro entrevistado. Los desarrollos que cumplieron con las características físicas y de actores descrita fueron los fraccionamientos Agaves-Villa Luna-El Capulín (Agaves) y Arvento, que corresponden a las localidades el Capulín y a la parte norte de la localidad de Cajititlán. Ambos fraccionamientos fueron construidos por la empresa Casas Geo, ${ }^{5}$ la mayor empresa mexicana de construcción de casas de interés social vigente hasta 2018, cuando se declaró en quiebra al asumir la insolvencia para continuar en el negocio y reconocer que no pueden generar más efectivo y captar recursos para liquidar sus deudas.

\footnotetext{
${ }^{5}$ La empresa creció exponencialmente desde la década de 1990 y llegó a construir más de 655000 casas en 52 ciudades de 16 estados. La empresa determinó que ofreció el servicio de vivienda a más de 2400000 personas (más de 1\% de la población). El modelo de negocio de Corporativo Geo se enfocó principalmente en el nivel asequible y segmentos económicos de pagos mensuales recaudados por el Instituto del Fondo Nacional de la Vivienda para los Trabajadores (Infonavit) y el Fondo de la Vivienda del Instituto de Seguridad y Servicios Sociales de los Trabajadores del Estado (Fovissste).
} 


\section{Fraccionamiento Arvento}

El fraccionamiento de Arvento actualmente conforma la parte norte de la localidad de Cajititlán, al norte del lago de Chapala. Tiene por punto central las coordenadas geográficas $20^{\circ} 26^{\prime} 45.62$ " latitud norte y $103^{\circ} 18$ '23.04” longitud oeste. Su superficie aproximada es de 116.89 hectáreas. Debido a que el último Censo de Población y Vivienda data del año 2010, donde se puede encontrar información específica a nivel de manzana, al igual que las áreas geoestadísticas básicas (Ageb), y dado a que el fraccionamiento creció entre el periodo 2010-2016, no se cuentan con datos completos de las variables de población. Sin embargo, el Inventario Nacional de Viviendas de Inegi (2016) señala que, de las 5165 casas particulares, 1349 están habitadas.

\section{Fraccionamiento Agaves-Villa Luna-El Capulín (Agaves)}

El fraccionamiento de Agaves se localiza en el sureste del AMG, pasando el aeropuerto. Tiene por punto central las coordenadas geográficas $20^{\circ} 28$ ' 17.28' latitud norte y $103^{\circ} 16^{\prime} 52.19$ ”' longitud oeste. Su superficie aproximada es de 176.32 hectáreas con una población de 8251 habitantes (Inegi, 2010). De acuerdo con el Inventario Nacional de Vivienda del Inegi (2016), las viviendas que se tenían eran 2193 habitadas de las 6796 casas particulares, es decir, se encuentran sin habitar, de acuerdo con estos datos, 4603 viviendas.

\section{Análisis de los criterios de expansión urbana dispersa \\ Centralidad}

En cuanto a la distancia lineal respecto al municipio central del AMG, el fraccionamiento de Agaves se encuentra a una distancia de entre 20 y 25 kilómetros y el fraccionamiento Arvento a una distancia de entre 25 y 31 kilómetros.

Mientras que la distancia lineal por colonia respecto al municipio central a la cabecera administrativa de Tlajomulco oscila entre los 11 y 21 kilómetros para ambos fraccionamientos como se muestra en las figuras 2 y 3 . 


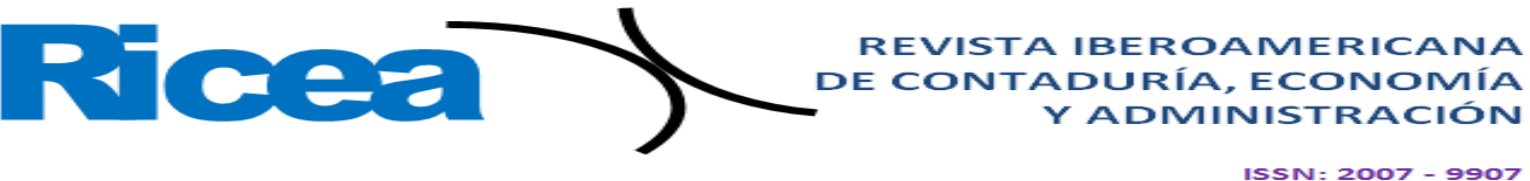

Figura 2. Distribución de los fraccionamientos respecto al AMG (variable de centralidad metropolitana)

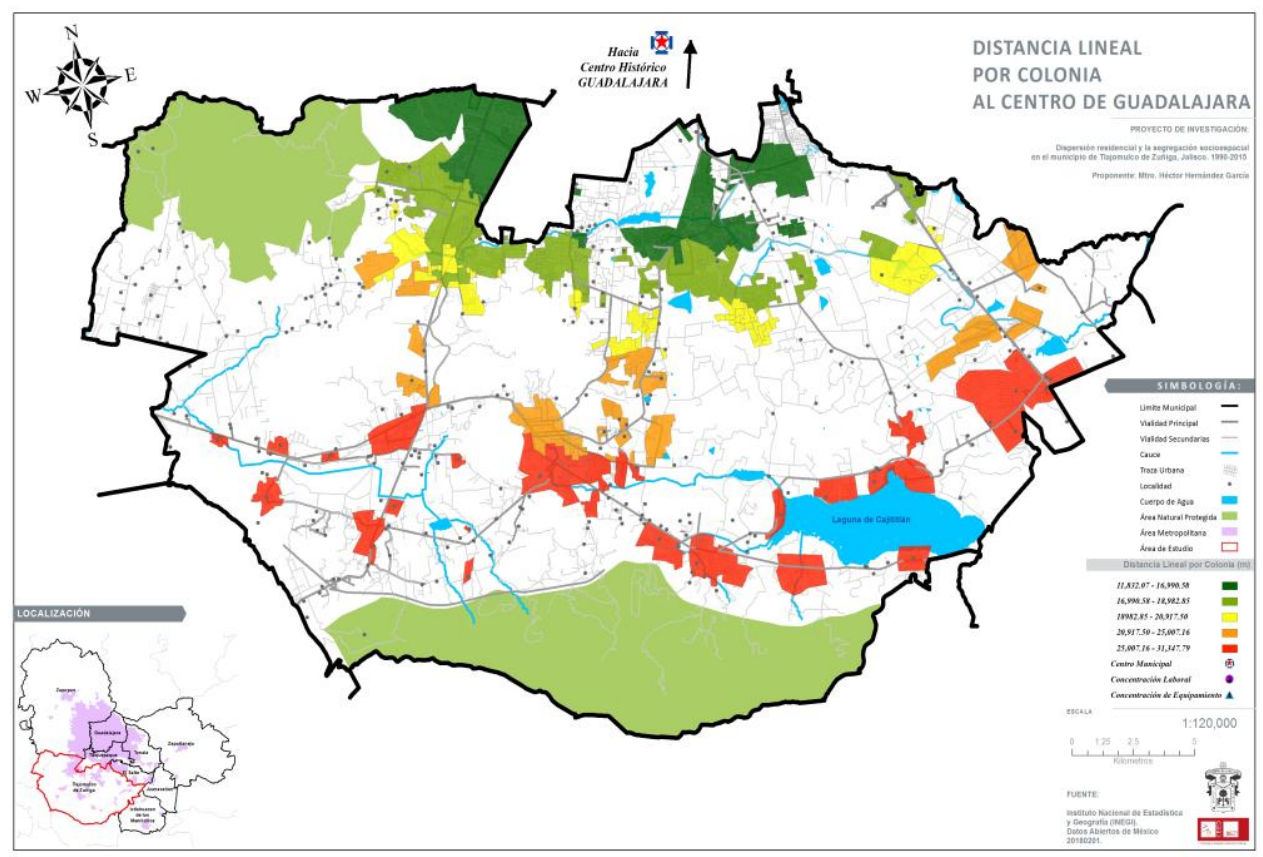

Fuente: Elaboración propia con base en Inegi (2010, 2013, 2016)

Figura 3. Distribución de los fraccionamientos respecto al centro de Tlajomulco de Zúñiga (variable de centralidad-municipal)

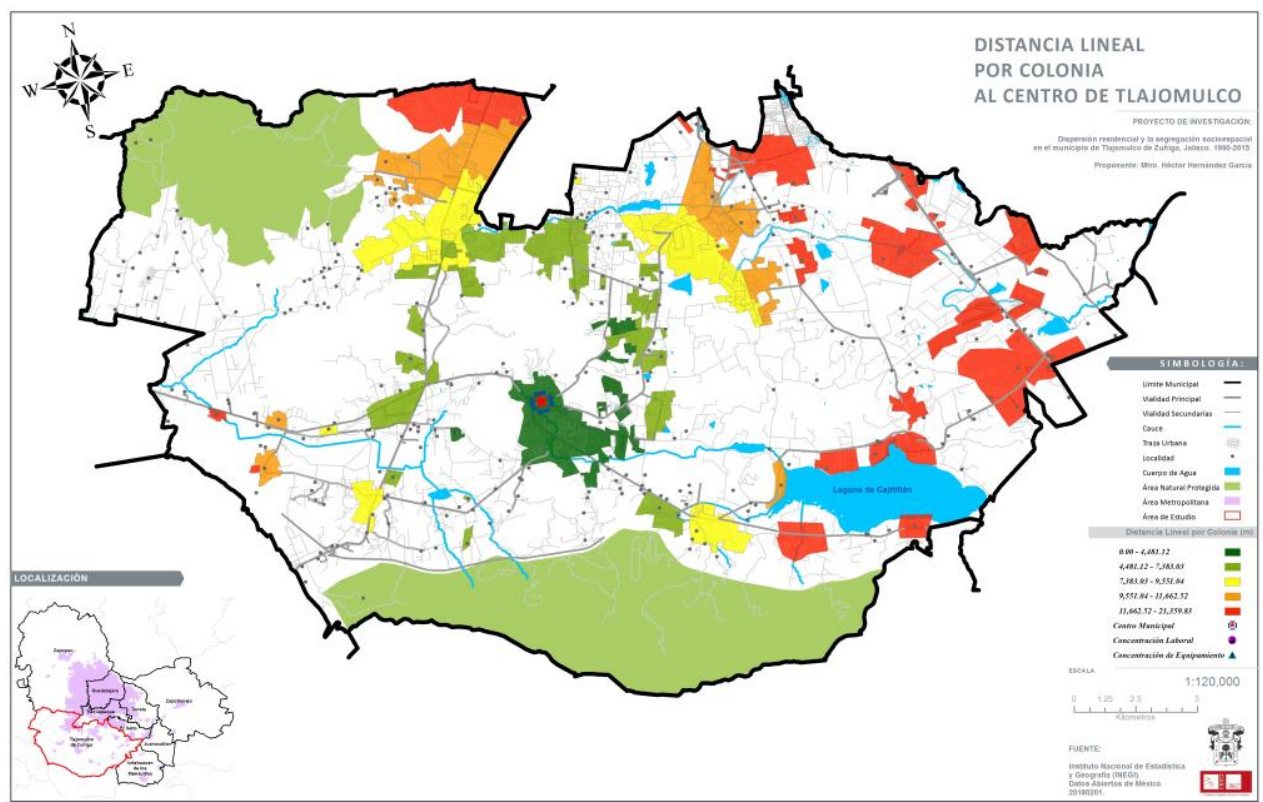

Fuente: Elaboración propia con base en Inegi (2010, 2013, 2016) 


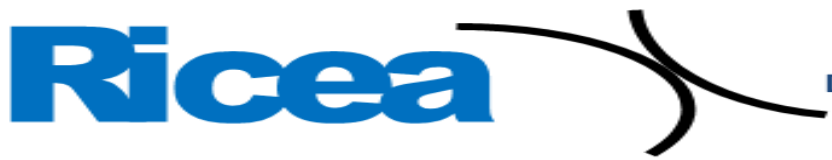

REVISTA IBEROAMERICANA DE CONTADURÍA, ECONOMÍA

Y ADMINISTRACIÓN

\section{Continuidad}

Diversos autores identifican la discontinuidad como uno de los atributos significativos de expansión. "Las ranas saltan más allá de subdesarrolladas tierra para dejar un mosaico de zonas desarrolladas y subdesarrolladas"; así, se construye un paisaje urbano de casas aisladas y de poca densidad (Jaeger y Schwick, 2014).

En este punto, se definirá el conjunto de asentamientos que presentan intersticios entre sí en un espacio planificado para su desarrollo. Los patrones tendrán puntuaciones bajas en esta dimensión. Cuerpos de agua, humedales, bosques, parques, laderas o suelos protegidos, autopistas, intercambios u otras reservas públicas e instalaciones no son consideradas interrupciones de patrones de desarrollo continuo. Cabe destacar que el área urbana del municipio de Tlajomulco de Zúñiga es de 15045.93 hectáreas: el tejido urbano discontinuo es de 6996.68 hectáreas y el tejido urbano continuo de 8049.25 hectáreas como se ilustra en la figura 4.

Figura 4. Área urbana continua y discontinua en el municipio de Tlajomulco de Zúñiga

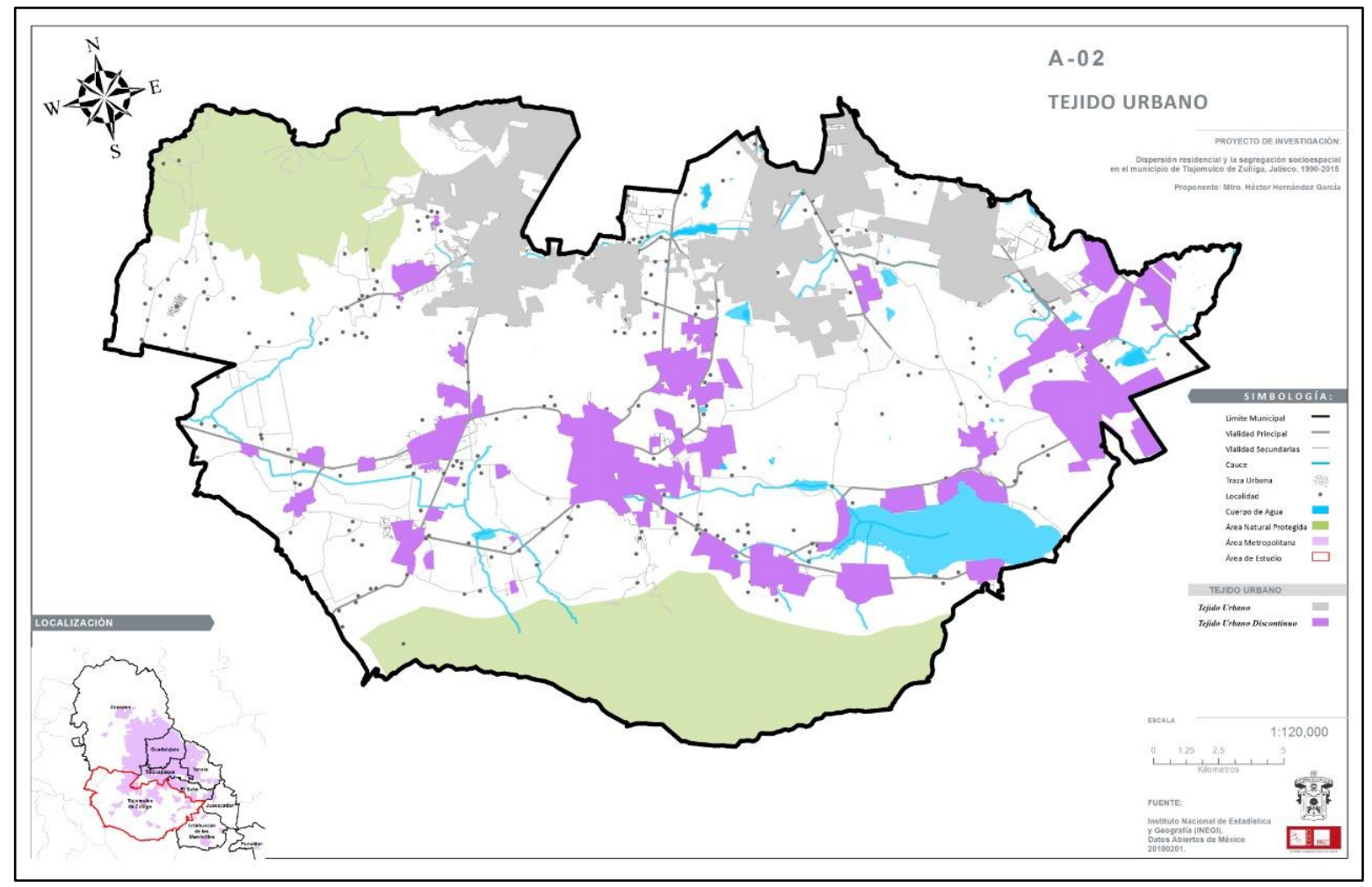

Fuente: Inegi (2016) 


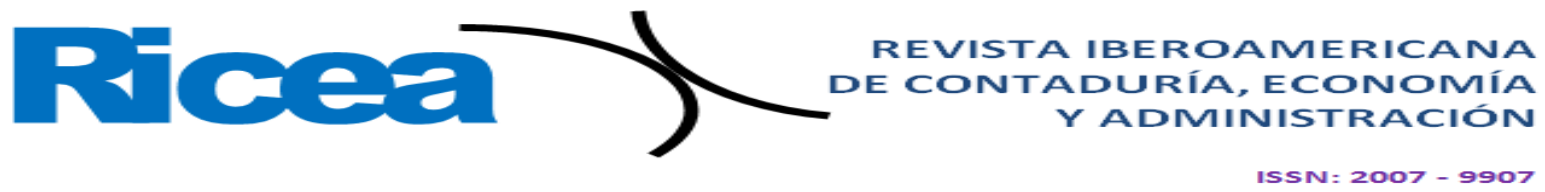

\section{La complejidad del plano urbano}

En cuanto a los índices de forma, se pretende medir la complejidad del polígono que delimita el espacio natural o forestal estudiado. Son numerosos los autores que han talado las teorías desarrolladas desde la ecología hasta el análisis de la ciudad dispersa, de acuerdo con Frenkel (2008). Las formas más compactas, con sentido geométrico, son las que presentan una relación de perímetro-área más pequeña, como en el caso de los de unos círculos o cuadrados que indican una menor dispersión.

Las manchas urbanas nos permiten diferenciar formas compactas como círculos o cuadrados. La forma más pequeña tan solo tiene un núcleo urbano con una forma rectangular casi perfecta y, por lo tanto, una complejidad mínima. El valor más elevado será el del único núcleo urbano con forma poligonal más tortuosa, que representa mayor complejidad.

El indicador de forma por ámbitos territoriales es el conjunto de núcleos urbanos de los municipios del sistema rural que presentan el valor más pequeño. De hecho, es en este ámbito que las manchas urbanas suelen ser más pequeñas y compactas. Por el contrario, la franja urbana es la que presenta el valor más alto, e indica más complejidad morfológica de las piezas urbanas en esta zona.

\section{La morfología del plano urbano del fraccionamiento Arvento}

Es un proyecto urbano sembrado en un polígono irregular, cuyo diseño interior obedece a elementos naturales, como el relieve natural y los cuerpos de agua que lo cruzan, por lo que se genera una traza de vialidades del sistema vial primario con formas orgánicas y, por extensión, manzanas y la disposición y sembrado de los edificios con formas irregulares y líneas sinuosas en algunos casos, y en otros, con tendencias ortogonales (figuras 5 y 7$)$. 


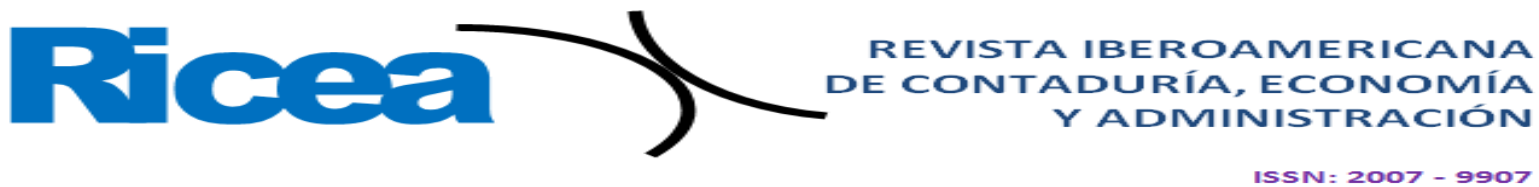

Figura 5. Fraccionamiento Arvento en el municipio de Tlajomulco de Zúñiga, Jalisco

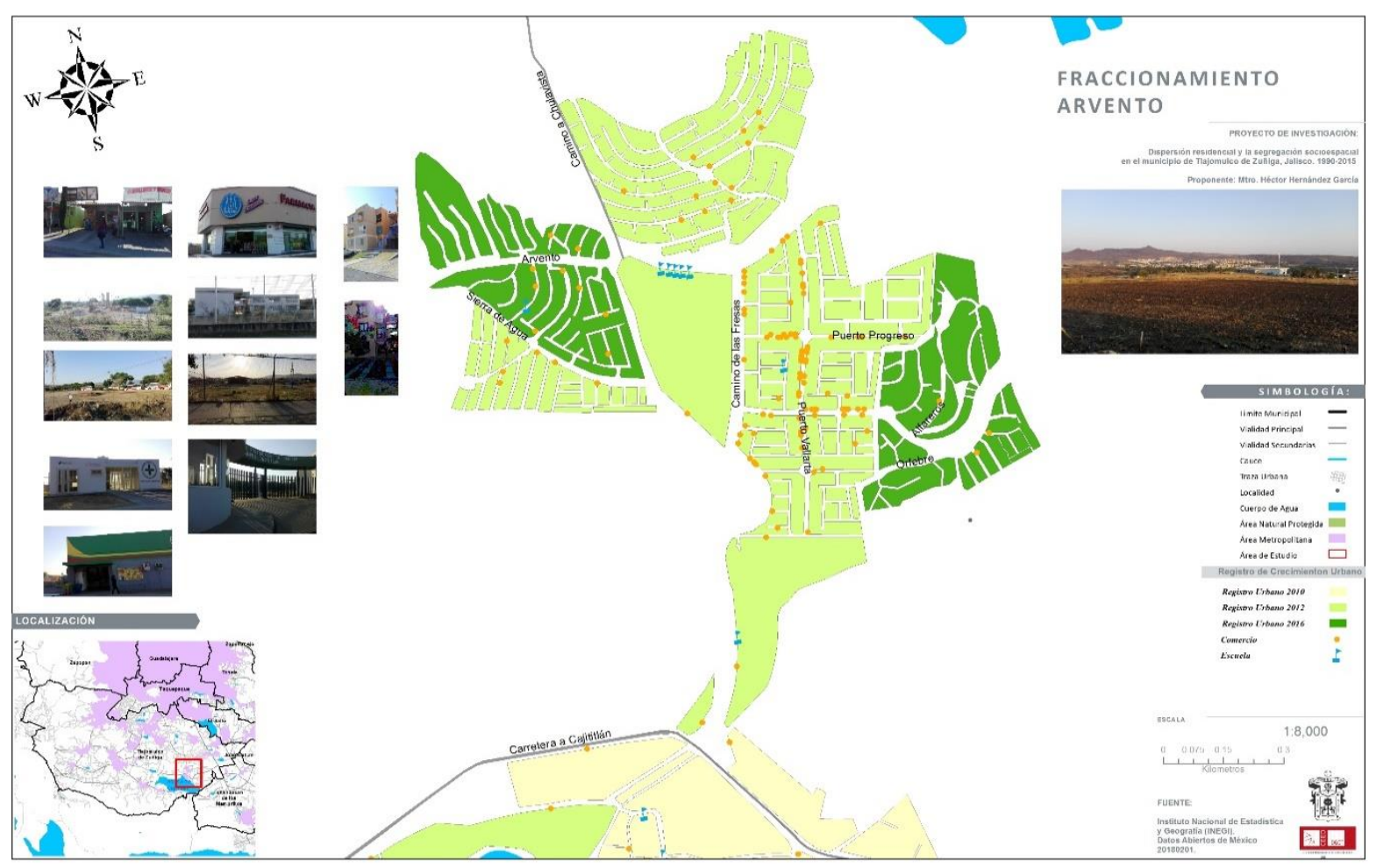

Fuente: Elaboración propia con base en Inegi (2016)

Las áreas públicas y el equipamiento urbano existente se concentran en su mayoría en la parte central del fraccionamiento, donde se encuentra la central de camiones de una sola ruta de camiones al interior denominada "Chapala" (figura 6).

Figura 6. Central de camiones cercana al fraccionamiento, parte oeste. (Existe solo una ruta de camiones al interior denominada Chapala)

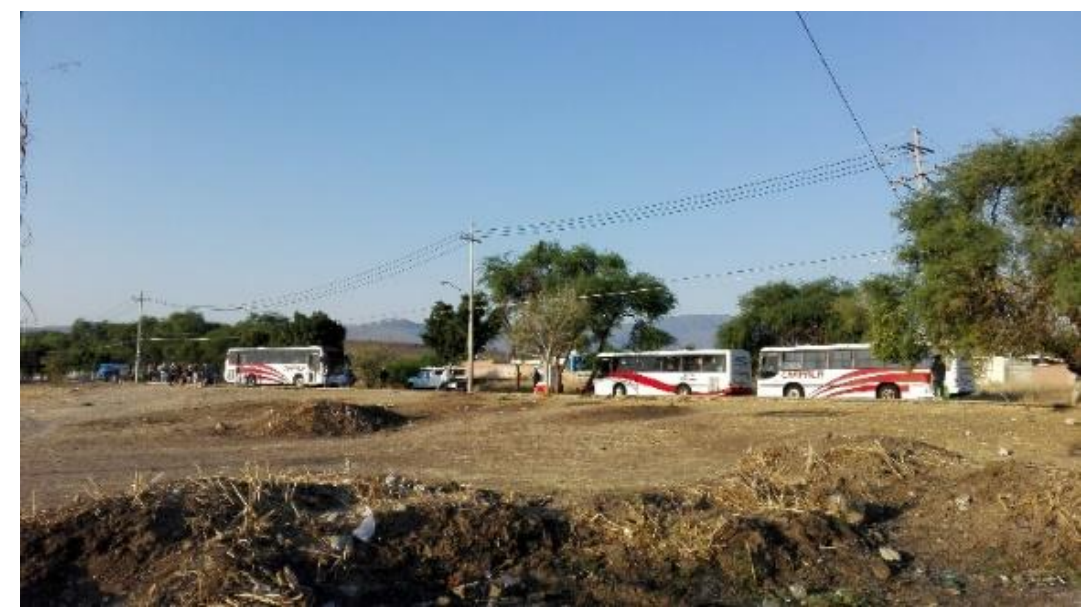

Fuente: Elaboración propia 


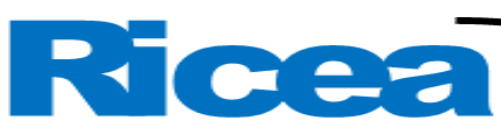

REVISTA IBEROAMERICANA DE CONTADURÍA, ECONOMÍA Y ADMINISTRACIÓN

Figura 7. Tipo de vivienda y servicios. (Espacios destinados a vehículos automotores no utilizados o subutilizados)

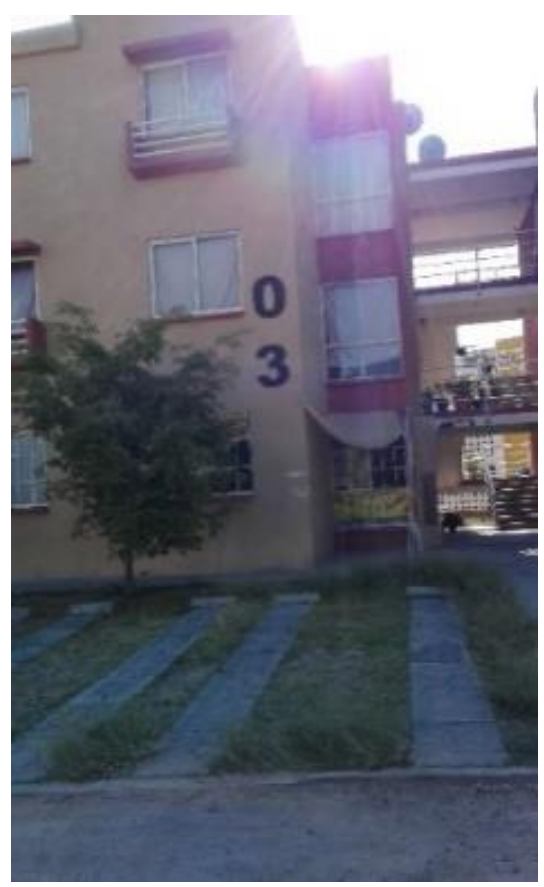

Fuente: Elaboración propia

\section{La morfología del plano urbano del fraccionamiento Agaves}

Es un proyecto urbano sembrado en un polígono irregular alargado de una longitud de 3.48 kilómetros, cuyo diseño interior obedece a dos lógicas: una de corte natural y otra a raíz de la traza de vialidades del sistema vial primario. Las manzanas, la disposición y sembrado de los edificios tienen formas regulares y líneas largas de vialidades con tendencias ortogonales como se muestra en la figura 8.

Las áreas públicas y el equipamiento urbano existente se concentran, en su mayoría, en la parte inicial. Ahí, podemos encontrar escuelas primarias y secundarias, sin embargo, la parada o central de camiones se encuentra al fondo del fraccionamiento, lo que dificulta las funciones y el traslado de algunas personas (figura 9). 


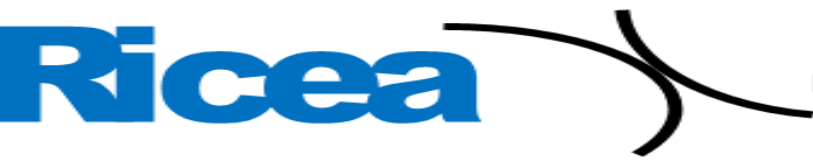

REVISTA IBEROAMERICANA DE CONTADURÍA, ECONOMÍA Y ADMINISTRACIÓN

ISSN = $2007-9907$

Figura 8. Fraccionamiento Agaves en el municipio de Tlajomulco de Zúñiga, Jalisco

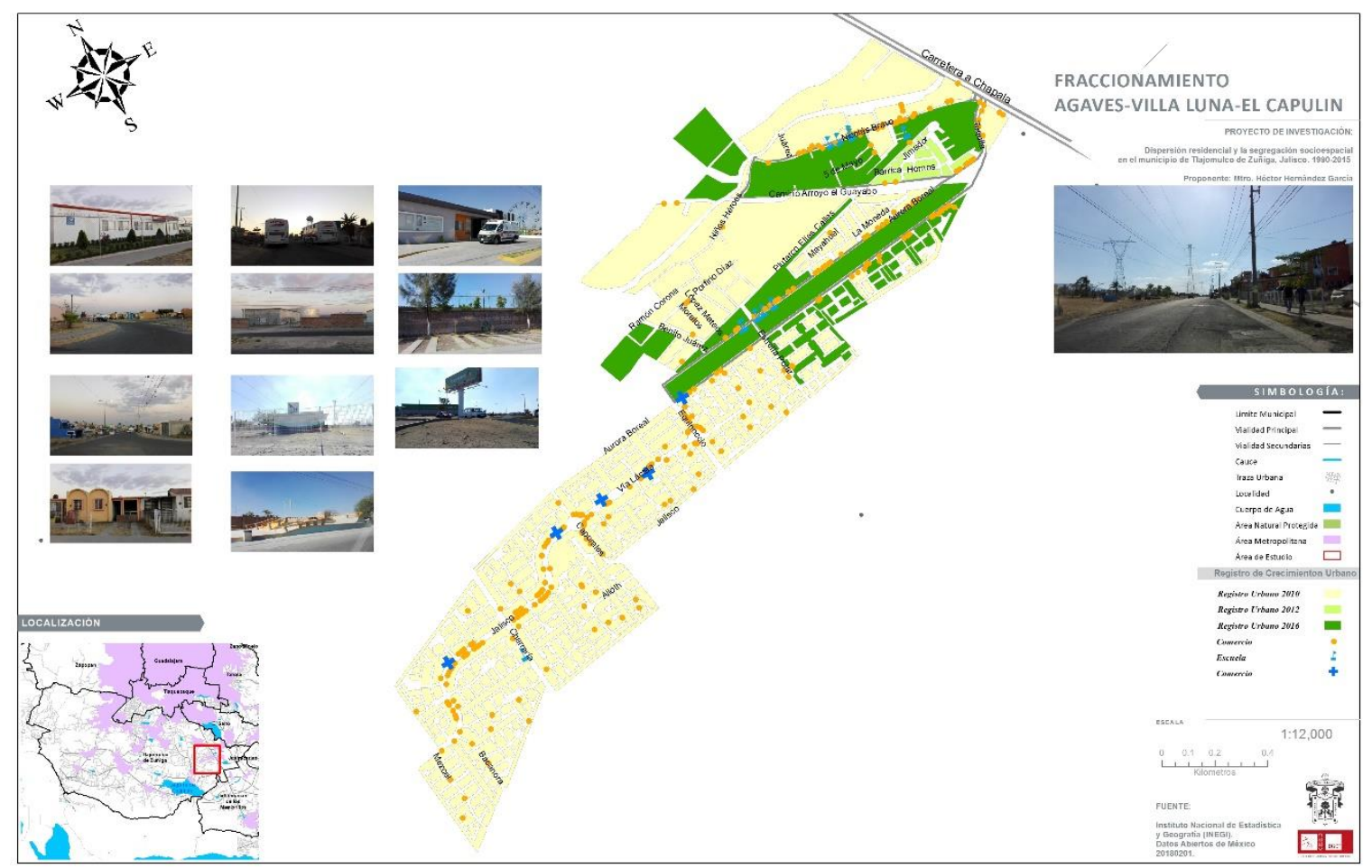

Fuente: Elaboración propia con base en Inegi (2016)

La morfología urbana consiste en un plano alargado con manzanas que siguen las vialidades isomorfas que forman caminos sinuosos donde el $80 \%$ corresponde a vivienda plurifamiliar de una sola planta. En el corredor de vivienda ubicado en la calle Vía Láctea se incorporan negocios de nivel vecinal (abasto diario semanal). 


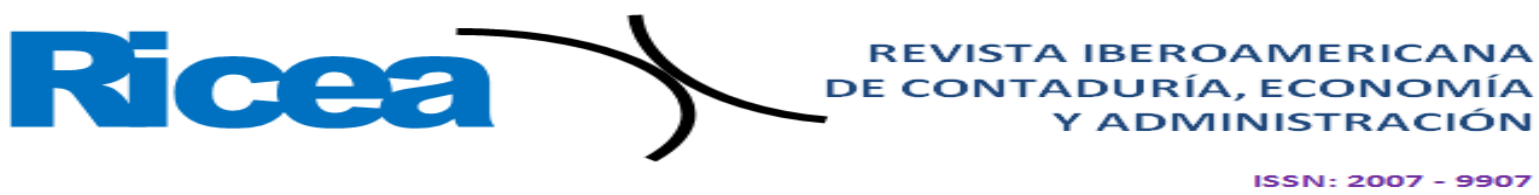

Figura 9. Entrada al fraccionamiento de Agaves. (Uso de automóviles particulares para dar servicio interurbano de la población que sale o entra al fraccionamiento)

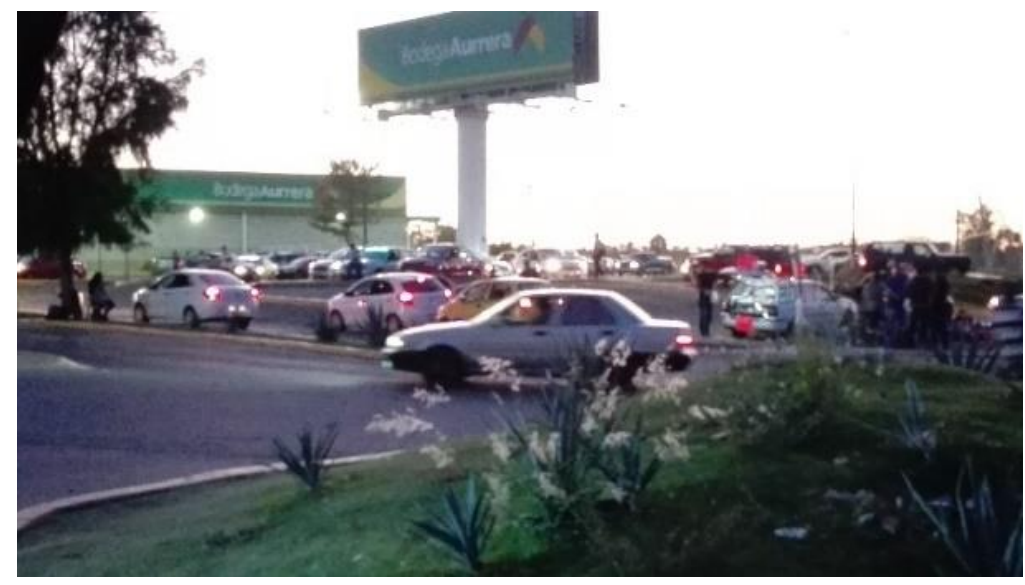

Fuente: Elaboración propia

Figura 10. Casa deshabitada en la sección final del fraccionamiento, al suroeste

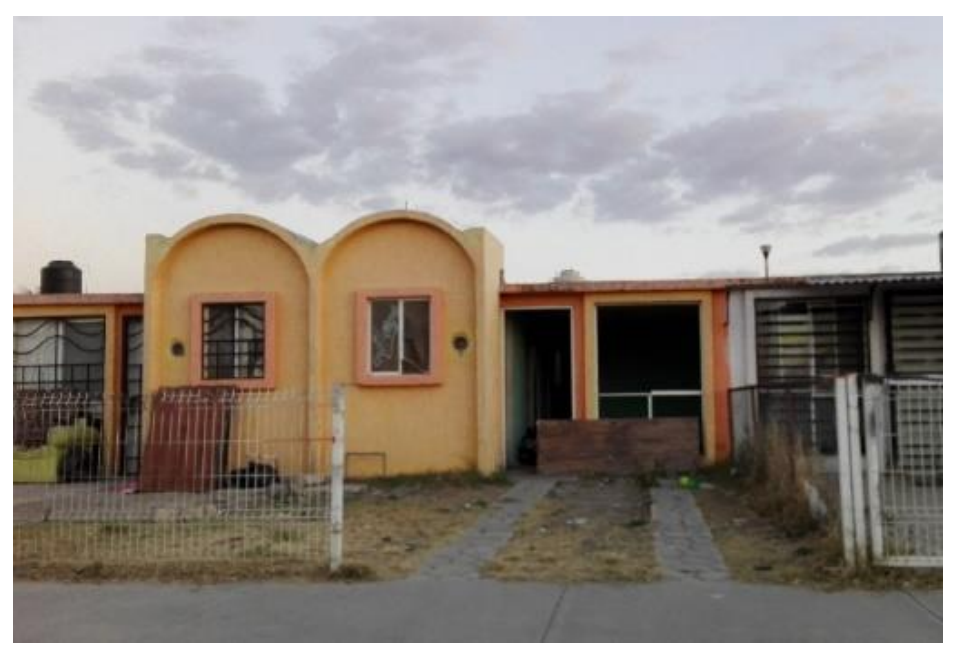

Fuente: Elaboración propia

\section{Valor de la vivienda}

Los hallazgos de información sobre las personas entrevistadas en materia de precio de la vivienda son los siguientes: en el fraccionamiento los Agaves se entrevistó a personas que pagaron 390000 pesos por su vivienda, 249000 pesos e incluso, luego de ser rebajadas, con subsidios emanados de la política de vivienda federal, 189000 pesos. 


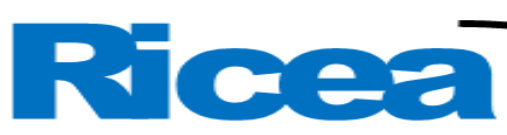

REVISTA IBEROAMERICANA DE CONTADURÍA, ECONOMÍA YADMINISTRACIÓN

En este fraccionamiento se identificó una persona que, dadas sus actividades laborales, permitió identificar un patrón de valores materiales y nivel de ingresos de sus residentes en función de su localización en el interior del fraccionamiento, que, como se señaló, presenta una forma alargada de grandes dimensiones (longitud de 3.5 kilómetros).

La entrevistada señaló que percibe personas con poder adquisitivo medio que viven cerca a la vialidad principal de acceso al fraccionamiento o salida a la carretera (ver figura 9), a diferencia de los residentes que habitan en viviendas que se encuentran a 3.5 kilómetros de distancia al punto de acceso (ver figura 10), lo cual implica una disminución en el valor de renta del inmueble con respecto a las viviendas cercanas a la vialidad principal.

El fraccionamiento Arvento fue promovido, por la propia empresa Casas Geo, desde el fraccionamiento de los Agaves como un espacio cercano a la laguna de Cajititlán, donde se podía comprar una vivienda con 270000 pesos o con subsidio podía reducirse a 220000 pesos.

También, se observaron pocos vehículos estacionados entre semana y fin de semana, cuando se realizaron las entrevistas como se ilustra en la figura 7, lo cual fue secundado por los entrevistados, que señalaron que el transporte público es lo más utilizado para comunicarse, siendo estos de carácter regional (Chapala). Cabe mencionar que en los dos casos se observó la problemática de largos tiempos de traslados a sus centros de trabajo, centros de salud y actividades recreativas y de ocio.

\section{Discusión}

El estudio exploratorio sobre las causas que originaron la dispersión socioespacial en Tlajomulco de Zúñiga nos permite entender que la accesibilidad es una variable indispensable para encontrar la lógica en la distribución de los asentamientos humanos. También, que las vialidades, de acuerdo con su cercanía o lejanía con el centro de negocios o servicios, establecen una relación directa con el valor de la vivienda. Es decir, la vivienda más cercana al centro tiende a un costo mayor que aquella alejada del centro, incluso al interior de los fraccionamientos se mantiene esta lógica. De aquí, un motivo para explorar la formación de segregación social en los diversos fraccionamientos.

Igualmente, algunos actores del mercado inmobiliario se rigen por una lógica de localización al establecer precios de acuerdo con el acceso, no solo al centro de negocios, 


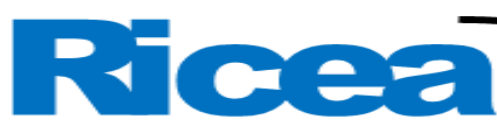

REVISTA IBEROAMERICANA DE CONTADURÍA, ECONOMÍA

sino también a los servicios básicos y de infraestructura. Es claro que, previo a la formalización de los asentamientos, no fue privilegiada la planificación urbana en el municipio, lo que causó una dispersión descontrolada de las poblaciones edificadas en su interior.

Consideramos que la fortaleza del estudio se encuentra en el manejo de dos dimensiones de análisis que se complementan (cuantitativa y cualitativa), bajo la premisa de analizar las relaciones entre procesos, políticas y variables de la expansión urbana dispersa respecto al valor de la vivienda, lo cual, en conjunto, permite avizorar dinámicas inmobiliarias y de consumo de la vivienda.

\section{Conclusiones}

Durante el periodo del 2000 al 2010, el Gobierno fue permisivo con el sector inmobiliario, es decir, otorgó muchos permisos de urbanización. En el caso de Tlajomulco de Zúñiga, el incremento de la población se dio a ritmos acelerados (tasa de crecimiento de $12.92 \%)$, por encima del promedio estatal y metropolitano. La población se triplicó en 10 años: de 123619 a 416626 habitantes.

La distribución de los asentamientos humanos en el municipio se estructuró en dos lógicas territoriales. La primera consistió en una serie de localidades urbanas con gran concentración poblacional orientadas a vialidades y accesos al AMG; y la segunda en localidades y asentamientos humanos alejados del continuo urbano, los cuales, además, en su estado actual, presentan formas irregulares y discontinuas del continuo urbano. De este último conjunto, se seleccionaron dos fraccionamientos alejados y discontinuos: Arvento y Agaves. En estos se identificó una relación entre variables espaciales medidas en la expansión urbana dispersa y el precio de la vivienda en el municipio de Tlajomulco de Zúñiga.

En cuanto a la variable de centralidad, conforme se incrementa la distancia respecto a los centros administrativos y de servicios, los costos de suelo y vivienda tienden a ser bajos. Lo anterior no puede ser determinante, dado que existen desarrollos de gran renombre y promotores del estatus socioeconómico medio-alto que presentan descentralización.

En cuanto a la variable de discontinuidad, se identifica que los desarrolladores van adquiriendo terrenos separados y sobre estos edifican fraccionamientos; al final, constituyen 


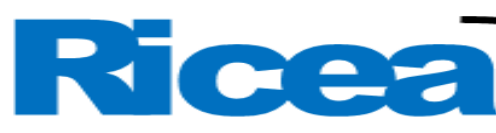

REVISTA IBEROAMERICANA DE CONTADURÍA, ECONOMÍA YADMINISTRACIÓN

$15 S N=2007-9907$

un escenario de asentamientos humanos dispersos. En el caso de los dos fraccionamientos analizados, fueron desarrollados y promovidos por la misma empresa Corporativo Geo, S.A. de C.V., mejor conocida como Casas Geo. En el análisis realizado se puede observar cómo existe un intersticio entre los dos fraccionamientos en cuestión, lo cual es objeto actual de especulación, por el posible uso futuro que se puede generar, un posible proyecto de vincularlos. Lo anterior refleja cómo el mercado y las propias empresas pueden ir incrementando el valor del suelo no urbanizado.

Respecto a la variable de la complejidad del plano urbano, esta se asocia con la determinación puntual de la localización de la vivienda en el contexto del fraccionamiento, papel relevante en la forma geométrica de estos, el trazo de las vialidades principales, así como el acceso o proximidad a servicios educativos, recreativos, culturales o de salud. El acceso a servicios básicos tiende a mejorar las condiciones de vida y crear un incremento en el valor de suelo y de la vivienda. En ese sentido, uno de los residentes entrevistados refiere que observa un patrón distinto de personas con poder adquisitivo que viven cerca a la vialidad principal de acceso al fraccionamiento o salida a la carretera respecto de los residentes que habitan en viviendas que se encuentran a tres kilómetros de distancia del punto de acceso, lo cual implica una disminución en el valor de renta del inmueble con respecto a las viviendas cercanas a la vialidad principal de acceso.

En general, se puede concluir que los fraccionamientos asentados en la porción sureste del municipio de Tlajomulco, en el contexto de la segunda metrópoli nacional, fueron impulsados por los actores inmobiliarios con la intención de aprovechar el valor del suelo, pero generando espacios alejados en tiempo y distancia de los centros administrativos y de servicios. Además, con formas y trazos urbanos internos que exacerban el círculo virtuoso de desvalorización del suelo y la vivienda, con dificultad para dotar de servicios de transporte y agua, lo que progresivamente segrega y raya en la exclusión de sus habitantes. En definitiva, el actor inmobiliario juega un papel relevante al decidir dónde y cómo construir y a quién venderle. 


\section{Referencias}

Alegría, T. y González, D. (2016). Interpretación del crecimiento urbano expansivo reciente. Ciudades, 27(111), 2-9.

Arenas, A. C. (2014). Métodos Mixtos de Investigación, Integración de la Investigación y la Investigación Cualitativa. Bogotá Colombia: Nueva Editorial Iztaccihuatl, S.A. de C.V.

Bazant, J. (2009). Periferias urbanas. Expansión urbana incontrolada de bajos ingresos y su impacto en el medio ambiente. México: Editorial Trillas.

Colmenares, L. M. (2015). Segregación aislada, mercado inmobiliario e intervención de actores en la dinámica socio-espacial. México: Prometeo Editores.

Comisión Nacional de Vivienda [Conavi]. (s. f.). ¿Qué hacemos? México: Gobierno de México. Recuperado de https://www.gob.mx/conavi/que-hacemos.

Cruz, H., Jiménez, E., Palomar, P. y Corona, J. (2008). La expansión metropolitana de Guadalajara en el municipio de Tlajomulco de Zúñiga (México). Serie Geográfica, (14), 223-234.

Eckert, J. K. (ed.) (1990). Tasación de la propiedad y administración de la evaluación. Chicago, United States: Asociación Internacional de Oficiales de la Evaluación.

Erba, D. A. (org.) (2013). Definición de políticas de suelo urbano en América Latina. Teoría y práctica. Vol. 1. Cambridge, Estados Unidos: Lincoln Institute of Land Policy. Recuperado de https://www.lincolninst.edu/sites/default/files/pubfiles/definicion-depoliticas-de-suelo-urbanas-full.pdf.

European Environment Agency [EEA]. (2006). Urban sprawl in Europe. The ignored challenge. Copenhagen, Denmark: European Environment Agency. Retrieved from https://www.eea.europa.eu/publications/eea_report_2006_10/eea_report_10_2006.p df/view.

Fitch, J. M. (2016). Patrón espacial del valor inmobiliario. Ciudades, 27(111), 10-17.

Frenkel, A. and Ashkenazi, M. (2008). Measuring urban sprawl: how can we deal with it? Environment and Planning B: Planning and Design. 35(1), 56-79.

Gielen, E. (2016) Costes del Urban Sprawl para la Administración local. Valencia, España: Universitat de València. Recuperado de 


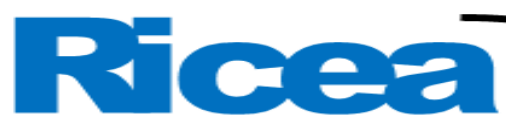

REVISTA IBEROAMERICANA DE CONTADURÍA, ECONOMÍA YADMINISTRACIÓN

https://play.google.com/books/reader?id=his6DgAAQBAJ\&hl=es\&printsec=frontco ver\&pg=GBS.PA3.

González, A. E. (2015). Formación de la periferia metropolitana sur-poniente de Toluca, 1970 a 2010. (tesis de licenciatura). Universidad Autónoma del Estado de México, Toluca. Recuperada de http://ri.uaemex.mx/bitstream/handle/20.500.11799/21902/UAEM-FAPUR-TESISGONZ\%C3\%81LEZ\%2C\%20ANAH\%C3\%8D.pdf?sequence=1\&isAllowed=y.

Harvey, E.O. and Clark, W. A. V. (1965). The Nature and Economics of Urban Sprawl. Land Economics, 41(1), 1-9.

Hernández, R., Fernández, C. y Baptista, P. (2010) Metodología de investigación. Ciudad de México, México: McGraw-Hill.

Instituto Nacional de Estadística y Geografía [Inegi]. (1990). XI Censo General de Población y Vivienda 1990. México: Instituto Nacional de Estadística y Geografía. Recuperado de https://www.inegi.org.mx/programas/ccpv/1990/default.html\#Tabulados.

Instituto Nacional de Estadística y Geografía [Inegi]. (2000). XII Censo General de Población y Vivienda 2000. México: Instituto Nacional de Estadística y Geografía. Recuperado de https://www.inegi.org.mx/programas/ccpv/2000/default.html\#Tabulados.

Instituto Nacional de Estadística y Geografía [Inegi]. (2010) XIII Censo de población y vivienda 2010. México: Instituto Nacional de Estadística y Geografía. Recuperado de https://www.inegi.org.mx/programas/ccpv/2010/default.html\#Tabulados.

Instituto Nacional de Estadística y Geografía [Inegi]. (2015). Encuesta intercensal 2015. México: Instituto Nacional de Estadística y Geografía. Recuperado de https://www.inegi.org.mx/programas/intercensal/2015/default.html\#Tabulados.

Instituto Nacional de Estadística y Geografía [Inegi]. (2016). Inventario Nacional de Viviendas 2016. México: Instituto Nacional de Estadística y Geografía.

Jaeger J. A. and Schwick, C. (2014). Improving the measurement of urban sprawl: Weighted Urban Proliferation (WUP) and its application to Switzerland. Ecological Indicators, 38, 294-308.

Mellado, R. (2013). La política de vivienda en las administraciones del Partido Acción Nacional: 2000-2012. Ponencia presentada en el Congreso Nacional de Vivienda 2013. Ciudad de México, del 12 al 14 de marzo de 2013. Recuperado de 


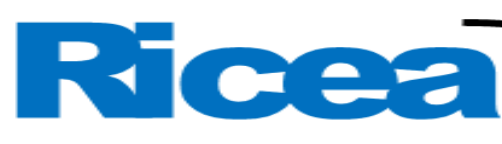

REVISTA IBEROAMERICANA DE CONTADURÍA, ECONOMÍA

https://www.puec.unam.mx/pdf/publicaciones_digitales/01_eje_1_politica_nacional _vivienda.pdf.

Monkkonen, P. y Comandon, A. (2016). Expansión urbana, segregación y estructura espacial. Ciudades, 27(111), 50-59.

Muñiz, M. A. I. (2006). Sprawl. Definiciones, causas y efectos. Barcelona, España: Departament d'Economia Aplicada de la Universitat Autònoma de Barcelona.

Muñiz, I. y García, M. A. (2013). Anatomía de la dispersión urbana en Barcelona. Revista EURE, 39(116), 189-219.

Sabatini, F. y Sierralta, C. (2006). Medición de la segregación residencial: meandros teóricos y metodológicos, y especificidad latinoamericana. En Pinto, J. (org.), Novas Metrópoles Paulistas - População, vulnerabiliade e segregação (pp. 169-195). São Paulo, Brasil: Universidade Estadual de Campinas

Secretaría de Desarrollo Social [Sedesol]. (2011). Estado de las ciudades de México 2011. México: Secretaría de Desarrollo Social.

Sierra, F. (1998). Función y sentido de la entrevista cualitativa en investigación social. En Galindo, L. J. (coord.), Técnicas de investigación en sociedad, cultura y comunicación (pp. 277-341). Ciudad de México, México: Consejo Nacional para la Cultura y Pearson Educación .

Smolka, M. (1981). Precio de la tierra y valorización inmobiliaria urbana: esbozo para una conceptualización del problema. Revista Interamericana de Planificación, 15(60), 70-89.

Zeng, C., He, S. and Cui, J. (2014) A Multi-Level and Multi-Dimensional Measuring on Urban Sprawl, A Case Study in Wuhan Metropolitan Área, Central China. Sustainability, 6, 3571-3598. 